\title{
Increased erythrocyte aggregation in diabetes mellitus and its relationship to glycosylated haemoglobin and retinopathy
}

\author{
M.Satoh ${ }^{2}$, K. Imaizumi ${ }^{1}$, T. Bessho ${ }^{2}$ and T.Shiga ${ }^{1}$ \\ ${ }^{1}$ Department of Physiology, School of Medicine, Ehime University and ${ }^{2}$ Division of Ophthalmology, Matsuyama Red Cross Hospital, \\ Ehime, Japan
}

\begin{abstract}
Summary. The velocity of erythrocyte aggregation in vitro was determined in 15 non-diabetic and 28 Type 1 (insulin-dependent) diabetic subjects, in autologous plasma under uniform shear flow using a rheoscope combined with a television image analyzer and a computer. In the diabetic subjects, the velocity of aggregation showed a significant correlation with the haemoglobin $A_{1}$ level, and was significantly increased in the proliferative retinopathy group. An alteration of plasma protein composition in the diabetic subjects (increase of $\emptyset$ - and
\end{abstract}

$\alpha_{2}$-fractions) also influenced erythrocyte aggregation, being related to the haemoglobin $A_{1}$ level. The percentage of the $\emptyset$-fraction and a parameter, $\left(\alpha_{2}+\emptyset\right) /$ albumin, defined by plasma electrophoresis, showed a strong correlation with the velocity of aggregation.

Key words: Diabetes, retinopathy, glycosylated haemoglobin, erythrocyte aggregation, plasma proteins, blood rheology.
The pathogenesis of diabetic microangiopathy is unclear. In diabetic microvascular disease, a disturbance of blood rheology has been reported, i.e., increased blood viscosity [1-3], increased serum viscosity [4] and increased blood dynamic viscoelasticity during clotting [5]. These rheological impairments may act as accelerating factors in diabetic microangiopathy, together with the increased oxygen affinity of diabetic erythrocytes [6, 7] due to the glycosylation of haemoglobin. If individual variation of the haematocrit is corrected, diabetic hyperviscosity may be caused by decreased erythrocyte deformability and/or by increased erythrocyte aggregation $[8,9]$. Although the increase of reversible aggregation in diabetes has been shown both in vitro [10 -12] and in vivo [13], a quantitative study of erythrocyte aggregation, taking into account protein glycosylation, has not been made.

We have recently devised a method for determining the velocity of erythrocyte aggregation in vitro [14]. Thus, we compared the velocity of erythrocyte aggregation in non-diabetic and diabetic subjects, and analyzed the factors influencing aggregation (i.e., glycosylation of haemoglobin, electrophoretic pattern of plasma proteins and haematological indices).

This study deals with the increased velocity of erythrocyte aggregation in diabetes as related to the haemoglobin $\mathrm{A}_{1}$ level. Apparent accelerating factors, such as changes in plasma proteins, are discussed.

\section{Subjects and methods}

\begin{abstract}
Subjects
Fifteen adult non-diabetic subjects and 28 patients with Type 1 (insulin-dependent) diabetes were studied. Their clinical details are given in Table 1. The diabetic patients were subdivided into three groups according to the results of retinal examination after pupillary dilatation by direct and indirect ophthalmoscopy, electroretinogram and fluorescein angiography: (1) patients without evidence of retinopathy, (2) patients with background retinopathy and (3) patients with active proliferative retinopathy. Informed consent was obtained for the study, which was carried out within 2 weeks of the eye examinations.
\end{abstract}

\section{Methods}

Erythrocytes and plasma: fresh venous blood was heparinized (10 units $/ \mathrm{ml})$; plasma was separated by centrifugation $(3,000 \mathrm{rev} / \mathrm{min}$ for $5 \mathrm{~min}$ at $\left.5^{\circ} \mathrm{C}\right)$, then again centrifuged $(15,000 \mathrm{rev} / \mathrm{min}$ for $20 \mathrm{~min}$ at $5^{\circ} \mathrm{C}$ ) to remove platelets; the buffy coat was removed; erythrocytes were washed twice with isotonic buffered saline solution $(93.4 \mathrm{mmol} / \mathrm{l}$ $\mathrm{NaCl}, 3.2 \mathrm{mmol} / 1 \mathrm{KCl}, 50 \mathrm{mmol} / 1 \quad \mathrm{Na}_{2} \mathrm{HPO}_{4}-\mathrm{NaH}_{2} \mathrm{PO}_{4}$ buffer, $5.0 \mathrm{mmol} / 1$ glucose, $\mathrm{pH} 7.4$ ).

Measurement of velocity of aggregation [14]: a rheoscope [9, 11, 12, 15 ], composed of a cone-plate viscometer with $0.8^{\circ}$ transparent cone (Model B, Tokyo Keiki, Tokyo, Japan) and an inverted microscope with $20 \times$ objective lens and $577 \mathrm{~nm}$ interference filter (Model IMT, Olympus Optics, Tokyo, Japan) was combined with a television image analyzer (Model Luzex 450, Toyo Ink, Tokyo, Japan) and a computer (Model HP-85, Hewlett-Packard, USA). The washed erythrocytes in autologous plasma (either $100 \%$ plasma or $70 \%$ diluted plasma with the buffered saline, final haematocrit of $0.26 \%$ ) were poured into the gap between the moving cone and glass plate on the microscope. Un- 
Table 1. Details of the subjects studied, $\mathrm{HbA}_{1}$ levels and results of velocity of aggregation measurements

\begin{tabular}{|c|c|c|c|c|c|c|c|c|}
\hline & & \multirow[t]{2}{*}{$\begin{array}{l}\text { Sex } \\
M: F\end{array}$} & \multirow[t]{2}{*}{$\begin{array}{l}\text { Age } \\
\text { (years) }\end{array}$} & \multirow{2}{*}{$\begin{array}{l}\text { Duration } \\
\text { of } \\
\text { diabetes } \\
\text { (years) }\end{array}$} & \multirow{2}{*}{$\begin{array}{l}\text { Fasting } \\
\text { blood } \\
\text { glucose } \\
(\mathrm{mmol} / 1)\end{array}$} & \multirow[t]{2}{*}{$\begin{array}{l}\mathrm{HbA}_{1} \\
(\%)\end{array}$} & \multicolumn{2}{|c|}{$\begin{array}{l}\text { Velocity of aggregation } \\
\left(\mu \mathrm{m}^{2} / \mathrm{min}\right)\end{array}$} \\
\hline & & & & & & & $\begin{array}{l}\text { In } 100 \% \\
\text { plasma }\end{array}$ & $\begin{array}{l}\text { In } 70 \% \\
\text { plasma }\end{array}$ \\
\hline Non-diabetic subjects & $(n=15)$ & $8: 7$ & $47.1 \pm 14.9$ & - & $\begin{array}{l}5.1 \pm 0.6 \\
(n=12)\end{array}$ & $6.6 \pm 1.1$ & $7.4 \pm 1.8$ & $5.6 \pm 1.4$ \\
\hline $\begin{array}{l}\text { Diabetic subjects } \\
\text { Without retinopathy } \\
\text { Background retinopathy } \\
\text { Proliferative retinopathy }\end{array}$ & $\begin{array}{l}(n=28) \\
(n=7) \\
(n=10) \\
(n=11)\end{array}$ & $\begin{array}{r}15: 13 \\
2: 5 \\
5: 5 \\
8: 3\end{array}$ & $\begin{array}{l}54.4 \pm 13.1 \\
57.1 \pm 14.7 \\
60.5 \pm 12.0^{c} \\
47.2 \pm 10.1\end{array}$ & $\begin{array}{r}8.7 \pm 8.2 \\
6.2 \pm 4.2 \\
7.5 \pm 7.8 \\
11.7 \pm 10.2 \\
(n=10)\end{array}$ & $\begin{array}{r}8.0 \pm 3.2^{\mathrm{b}} \\
10.8 \pm 4.1^{\mathrm{a}} \\
7.1 \pm 2.4^{\mathrm{c}} \\
7.1 \pm 2.1^{\mathrm{b}}\end{array}$ & $\begin{array}{l}9.4 \pm 2.6^{\mathrm{b}} \\
9.3 \pm 2.7^{\mathrm{b}} \\
9.3 \pm 2.9^{\mathrm{b}} \\
9.5 \pm 2.5^{\mathrm{a}}\end{array}$ & $\begin{array}{c}8.8 \pm 2.5 \\
8.3 \pm 1.8 \\
7.5 \pm 1.7 \\
10.3 \pm 2.8^{b}\end{array}$ & $\begin{array}{l}6.0 \pm 1.5 \\
5.5 \pm 1.4 \\
5.9 \pm 1.8 \\
6.4 \pm 1.3\end{array}$ \\
\hline Total & $(n=43)$ & $23: 20$ & $\begin{array}{l}51.5 \pm 14.0 \\
(27-76)\end{array}$ & $\overline{(0.5-30)}$ & $\begin{array}{l}7.1 \pm 2.9 \\
(n=40) \\
(4.1-17.6)\end{array}$ & $\begin{array}{l}8.4 \pm 2.6 \\
(4.9-15.3)\end{array}$ & $\begin{array}{c}8.3 \pm 2.3 \\
(4.6-13.7)\end{array}$ & $\begin{array}{l}5.9 \pm 1.5 \\
(3.4-8.9)\end{array}$ \\
\hline
\end{tabular}

Results are expressed as mean \pm SD with range in parentheses.

${ }^{\mathrm{a}} p<0.001,{ }^{\mathrm{b}} p<0.01,{ }^{\mathrm{c}} p<0.05$, statistical significance between the non-diabetic group and each diabetic group

der a uniform shear flow (shear rate of $7.5 \mathrm{~s}^{-1}$ ), the erythrocytes gradually formed one-dimensional face-to-face aggregates (rouleaux), then developed three-dimensional aggregates (mostly made of only a few rouleaux).

The number (count) and the projected area (area) of such moving particles on the television images were encoded consecutively and transferred to the computer. The increment of area/count during the stage of rouleaux formation was adopted as the velocity of erythrocyte aggregation (in $\mu \mathrm{m}^{2} / \mathrm{min}$ ). The measurements were performed at $25^{\circ} \mathrm{C}$. The reproducibility of the velocity measurement was reasonable: coefficient of variation $<8 \%$. The experimental details and kinetics have been described elsewhere $[14,16]$.

\section{Other measurements}

The haemoglobin $\mathrm{A}_{1}\left(\mathrm{HbA}_{1}\right)$ level was determined with a Bio-Rad kit (Bio-Rad Laboratories, Richmond, California). This method determines the fast haemoglobin content, reflecting the concentration of $\mathrm{HbA}_{1 \mathrm{c}}[17-19]$. Electrophoresis of plasma and serum proteins was carried out on a cellulose acetate membrane. Fasting blood glucose was determined by an automatic glucose analyzer (Newglucolosa, Sinotest, Tokyo, Japan). Haematocrit and haematological indices were determined by an automatic counter (Model S, Coulter Electronics, Hialeah, Florida). All the above measurements were made on the same fasting blood sample used for the aggregation study. The fibrinogen level was determined by the method of Parfentjef et al. [20], on a different date, but within 2 weeks.

\section{Statistical analyses}

Group means and standard deviations $( \pm S D)$ are given in the Tables. Statistical significance was evaluated by Student's t-test.

\section{Results}

\section{Relationship between $\mathrm{Hb} A_{1}$ level and diabetes}

Fasting blood glucose and $\mathrm{HbA}_{1}$ levels are summarized in Table 1. The $\mathrm{HbA}_{1}$ level was significantly elevated in all diabetic groups compared with the non-diabetic group, although there was no significant difference between the diabetic groups. The fasting blood glucose levels showed a similar tendency. There was a correla- tion between fasting blood glucose and $\mathrm{HbA}_{1}$ levels (for all subjects, $r=0.54, n=40, p<0.01$ and for diabetic subjects, $r=0.40, n=28, p<0.05$ ), although these values were not as high as some in the literature [18]. There was no correlation between age, duration of diabetes and fasting blood glucose or $\mathrm{HbA}_{1}$ levels.

\section{Relationship between erythrocyte aggregation and diabetes}

Typical patterns of erythrocyte aggregation of a nondiabetic and a diabetic subject, as displayed by the method used, are shown in Figure 1. In a subject with proliferative retinopathy (Fig.1, right panels): (a) rouleaux were formed rapidly and the maximal count was less, (b) three-dimensional aggregates were developed and the decay rate of the count was faster, and (c) the increment of area/count was higher and the standard deviation of area/count became greater at a later stage, compared with a non-diabetic subject (Fig. 1, left panels). Such an accelerated pattern could be observed by adding excess fibrinogen [14] or immunoglobulin [21] to normal plasma, thus agreeing with the rheoscopic observation in diabetic retinopathy [12]. According to our kinetic study [16], the increment of area/count increased proportionally with the association rate constant of erythrocyte polymerization, when only rouleaux were formed without developing three-dimensional aggregates. However, in the present study, especially in $100 \%$ plasma, three-dimensional aggregates developed, thus the velocity determined in $70 \%$ plasma gave a better measure than that determined in $100 \%$ plasma, though the two values correlated well $(r=0.47, n=43, p<0.005)$.

As summarized in Table 1, the velocity of aggregation in $100 \%$ plasma of the proliferative retinopathy group was significantly higher than that of the non-diabetic group, confirming a previous rheoscopic observation [12]. The velocity in $70 \%$ plasma also changed with 
the degree of retinopathy, although without statistical significance. However, the velocity in $70 \%$ plasma was significantly correlated with the $\mathrm{HbA}_{1}$ level in the diabetic groups, but not in the non-diabetic group (Table 2). On the other hand, the fasting blood glucose level showed no correlation with the velocity of aggregation.

\section{Relationship between erythrocyte aggregation and plasma proteins}

The electrophoretic patterns of plasma and serum proteins were essentially similar in the present study. No particular alteration of electrophoretic patterns was ob-
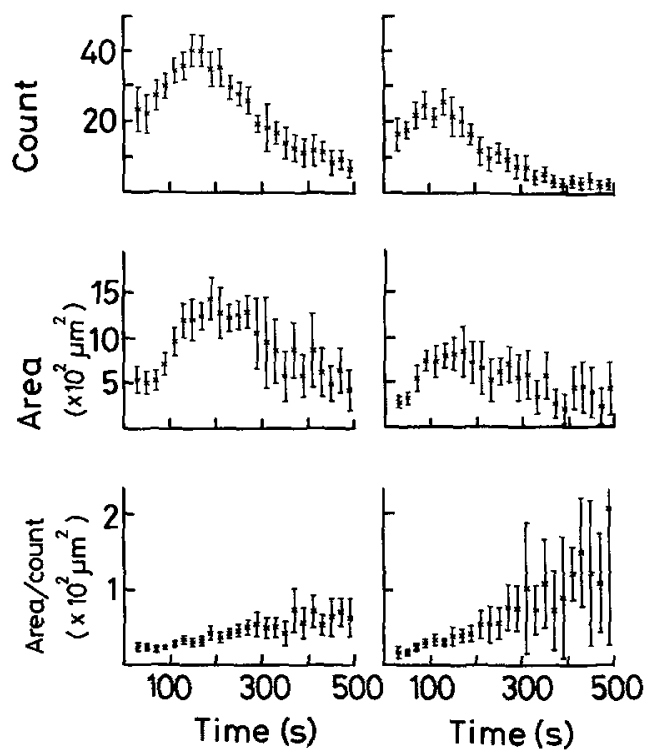

Fig. 1. Typical patterns of erythrocyte aggregation. Left panels: a non-diabetic subject; right panels: a diabetic patient with proliferative retinopathy. The patterns are displayed by mean $(x) \pm S D$ of $15-16$ consecutive television images during $20 \mathrm{~s}$. The increment of area/count in the range $100-300 \mathrm{~s}$ [14] is adopted as the velocity of aggregation. The measurements were carried out in $70 \%$ diluted autologous plasma at a haematocrit of $0.26 \%$ under a shear rate of 7.5 per s at $25^{\circ} \mathrm{C}$ served among the four groups, except for a significant increase of the $\alpha_{2}$-fraction in the proliferative retinopathy group $(7.8 \pm 1.8 \%, n=9)$ compared with the nondiabetic group $(6.4 \pm 1.1 \%, n=15 ; p<0.01)$.

In the diabetic subjects, the velocity of aggregation in $70 \%$ plasma showed a significant correlation with $\alpha_{1}$ $(r=-0.45, n=23, p<0.05)$ and $\emptyset-(r=0.59, n=23$, $p<0.01$ ) fractions. A change in the plasma or serum albumin/globulin ratio showed a slight tendency to reduce the aggregation, although statistically not significant. In the diabetic groups, a combined parameter (sum of $\alpha_{2}$-globulin and fibrinogen fractions) /(albumin fraction) denoted as $\left(\alpha_{2}+\emptyset\right) /$ albumin, showed a significant positive correlation with the velocity of aggregation in 70\% plasma (Table 2) and was also significantly correlated with the $\mathrm{HbA}_{1}$ level $(r=0.53, n=23, p<$ $0.01)$.

\section{Relationship between erythrocyte aggregation and haematological indices}

The haematological indices showed no significant correlation with the presence of diabetic complications, nor with age, sex or plasma proteins. However, in the non-diabetic group, mean corpuscular volume showed a significant correlation $(r=-0.68, n=13, p<0.02)$ with the velocity of aggregation in $70 \%$ plasma: i.e., the larger erythrocyte volume tended to reduce the aggregation. The mean corpuscular haemoglobin showed a similar tendency, because of the correlation between cell volume and haemoglobin concentration (for the non-diabetic group, $r=0.94, n=13, p<0.001)$. On the other hand, the haematological indices showed no significant correlation with the velocity of aggregation in the diabetic patients.

\section{Discussion}

The determination of the velocity of erythrocyte aggregation under a uniform shear flow provides a quantitative scale, which is related to the blood viscosity at low

Table 2. The relationship between the velocity of aggregation and various factors

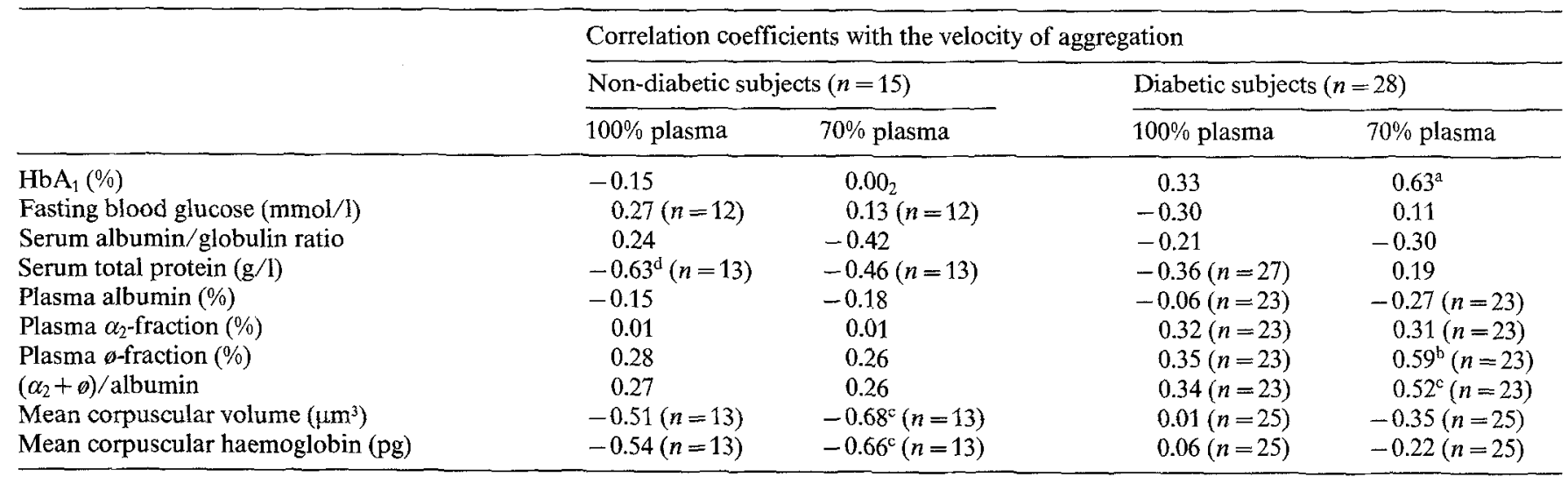

${ }^{\mathrm{a}} p<0.001,{ }^{\mathrm{b}} p<0.005,{ }^{\mathrm{c}} p<0.02,{ }^{\mathrm{d}} p<0.05$, statistical significance by t-test 
shear rates and to sludging of blood in the microcirculation. The velocity of aggregation in 100\% autologous plasma was significantly higher in the proliferative retinopathy group, and the velocity in $70 \%$ diluted plasma varied with the degree of diabetic retinopathy, although not significantly (Table 1 ), thus confirming an earlier observation [12].

We now report a significant, positive correlation between the $\mathrm{HbA}_{1}$ level and the velocity of aggregation in diabetic subjects. Such rheological disturbance related to high a $\mathrm{HbA}_{1}$ level may be one of the factors important in the development of diabetic microangiopathy [1, $2,12,13]$, together with poor oxygen supply caused by the high oxygen affinity of $\mathrm{HbA}_{1}[6,7,22]$ (due to lowered oxygen dissociation rate [22] and to poor response against 2,3-diphosphoglycerate [7, 22]). Furthermore, it may lead to the impairment of erythrocyte survival [23].

The velocity of aggregation correlated with the $\mathrm{HbA}_{1}$ level, but not with the fasting blood glucose level (Table 2). This discrepancy may arise from several factors. (a) The glucose levels of out-patients (most of the non-retinopathy group) are poorly controlled, but those of hospital in-patients (all of the proliferative retinopathy group and many of the background retinopathy group) are better controlled. However, as judged from $\mathrm{HbA}_{1}$ levels, the glucose levels were probably high before admission to hospital. (b) The best correlation coefficient between the blood glucose level and the $\mathrm{HbA}_{1}$ level $(r=0.8)$ is obtained by taking means of several fasting blood glucose or peak glucose levels during glucose tolerance testing [18]. In our subjects, only the fasting glucose levels of the same fasting blood sample for the aggregation study were available, particularly in out-patients: thus, the correlation coefficient was low $(r=0.4$, though statistically significant). (c) Since the $\mathrm{HbA}_{1}$ level is recognized as reflecting the glucose level over the previous several weeks $[17,18]$, the correlation between the $\mathrm{HbA}_{1}$ level and the velocity of aggregation (or the amount of fibrinogen) was still high in our diabetic patients (Table 2), despite combining data from out-patients and in-patients.

Erythrocyte aggregation is influenced by many factors. In general, aggregation results from the bridging of high molecular weight proteins, intercalating between the surfaces of adjacent erythrocytes, but opposed by (a) the electrostatic repulsion due to surface charges, (b) the shear stress in flow and (c) the resistance against bending in the erythrocytes [24]. Concerning the effect of plasma proteins on aggregation, it has been shown that fibrinogen, $\alpha_{2}$ - and $\gamma$-globulin possess an accelerating effect [25-28], which has been quantitatively confirmed using the present apparatus [14, 21]. In our experiments, the final haematocrit and the shear rate were constant, and $\mathrm{pH}$ of the medium was fairly constant (individual variation $<0.2 \mathrm{pH}$ unit). Therefore, possible causes of the increased erythrocyte aggregation in cases with diabetic complications include the following factors: the changes of plasma proteins (both quantitative and qualitative), the electrostatic properties of the erythrocyte surface and cellular deformability.

The alteration of plasma protein composition, including a decrease of albumin and an increase of the $\alpha_{2}$-fraction and fibrinogen (and to a lesser extent, the changes of $\beta$ - and $\alpha_{1}$-fractions), has been reported previously $[1,4,10,12,13]$. The percentage of the $\not$-fraction (or the amount of fibrinogen) was positively correlated with the velocity of aggregation in our diabetic subjects (Table 2). Therefore, the parameter, $\left(\alpha_{2}+\emptyset\right) /$ albumin, correlated well with the velocity of aggregation and with the $\mathrm{HbA}_{1}$ level. The dependency of the velocity of aggregation on protein concentration is complex; e.g., for a single protein (such as fibrinogen or immunoglobulin [21]), the velocity increased exponentially with an increase in the protein concentrations, while for plasma, the velocity decreased non-linearly upon successive dilution of plasma and the velocity in $70 \%$ diluted plasma seemed to be a better measure than that in $100 \%$ plasma (because of lesser three-dimensional aggregates).

Concerning cellular deformability, we have shown that the oxidative cross-linking of spectrin decreases the deformability and reduces the velocity of aggregation [29]. In diabetes, the viscosity of a haemolysate of high $\mathrm{HbA}_{1}$ level blood is slightly higher than that of normal blood [30]; this increase of intracellular viscosity may result in decreased deformability (together with the glycosylation of membrane protein [31], such as spectrin [32], and with the decreased membrane fluidity [33]), and may reduce the velocity of aggregation. However, the cross-linking of spectrin could not be detected and the difference in mean $\mathrm{HbA}_{1}$ levels between the nondiabetic and the diabetic groups was only $3 \%$ (Table 1 ). Thus the subtle change in deformability, if any, may not affect the velocity of aggregation.

The non-enzymatic glycosylation of erythrocyte membrane proteins $[31,32]$ and plasma proteins $[34,35]$, associated with diabetes and perhaps proportional to the $\mathrm{HbA}_{1}$ level, might contribute to the increased aggregation. However, at present it is not certain whether or not such glycosylation can enhance intercellular bridging and/or reduce electrostatic surface repulsion.

The negative correlation between the velocity of aggregation and the mean corpuscular volume in the non-diabetic subjects suggests an effect of erythrocyte size and shape [14]. However, in the diabetic subjects, the haematological indices did not correlate with the velocity of aggregation, nor with the $\mathrm{HbA}_{1}$ level. Possibly, the alteration of other factors (e.g., plasma protein composition) may be a stronger influence than the effect of erythrocyte shape.

In conclusion, these results show that the increased erythrocyte aggregation (a) correlated significantly with the increased $\mathrm{HbA}_{1}$ level in diabetic subjects and (b) was related to the degree of diabetic retinopathy. The altered plasma electrophoretic patterns, especially increased fibrinogen, could partly explain the increased aggregation in diabetes, but the contribution of other 
factors, such as glycosylation of membrane and plasma proteins, remains unknown.

Acknowledgements. The authors are indebted to Dr. N. Maeda for helpful advise and to Miss M. Sekiya for technical assistance. They are grateful to Mrs. S.Spencer-Smith and Dr. H.J. Bodansky for correcting the manuscript. This work was supported, in part, by grants from the Ministry of Education, Science and Culture of Japan and from the Ehime Medical Foundation.

\section{References}

1. Skovborg F, Nielsen AV, Schlichtkull J, Ditzel J (1966) Blood viscosity in diabetic patients. Lancet 1:129-131

2. Dintenfass L (1977) Blood viscosity factors in severe nondiabetic and diabetic retinopathy. Biorheology 14: 151-157

3. McMillan DE, Utterback NG, Stocki J (1980) Low shear rate blood viscosity in diabetes. Biorheology 17: 355-362

4. McMillan DE (1974) Disturbance of serum viscosity in diabetes mellitus. J Clin Invest 53: 1071-1079

5. Isogai Y, Iida A, Michizuki, K, Abe M (1976) Hemorheological studies in the pathogenesis of diabetic microangiopathy. Thrombosis Res 8 (Suppl): 17-24

6. Ditzel J (1979) Changes in red cell oxygen release capacity in diabetes mellitus. Fed Proc 38: 2484-2488

7. McDonald MJ, Bleichman M, Bunn HF, Noble RW (1979) Functional properties of the glycosylated minor components of human adult hemoglobin. J Biol Chem 254: 702-707

8. Chien S (1975) Biophysical behavior of red cells in suspension. In: Surgenor DM (ed) The red blood cells, 2nd edn, vol 2. Academic Press, New York, pp 1031-1133

9. Schmid-Schönbein H (1976) Microrheology of erythrocytes, blood viscosity and the distribution of blood flow in microcirculation. In: Guyton AC (ed) Cardiovascular physiology II. University Press, Baltimore, pp 1-62

10. van Haeringen NJ, Oosterhuis JA, Terpstra J, Glasius E (1973) Erythrocyte aggregation in relation to diabetic retinopathy. Diabetologia $9: 20-24$

11. Schmid-Schönbein H, Holger E (1976) Red-cell aggregation and red-cell deformability in diabetes. Diabetes 25 (suppl) 2: 897-902

12. Little HL (1976) The role of abnormal hemorheodynamics in the pathogenesis of diabetic retinopathy. Trans Am Ophthalmol Soc $74: 573-636$

13. Ditzel J, Moinat P (1959) Changes in serum proteins, lipoproteins and protein-bound carbohydrates in relation to pathological alterations in the microcirculation of diabetic subjects. J Lab Clin Med $54: 843-859$

14. Shiga T, Imaizumi K, Harada N, Sekiya M (1983) Kinetics of rouleaux formation using TV image analyzer. I. Human erythrocytes. Am J Physiol 245: H252-H258

15. Schmid-Schönbein H, Gaehtgens P, Hirsch H (1967) Eine neue Methode zur Untersuchung der rheologischen Eigenschaften von Erythrozyten-Aggregaten. Pflügers Arch 297: 104-114

16. Shiga T, Imaizumi K, Maeda N, Kon K (1983) Kinetics of rouleaux formation using TV image analyzer. II. Rat erythrocytes. Am J Physiol 245: H259-H264

17. Bunn HF, Gabbay KH, Gallop PM (1978) The glycosylation of hemoglobin: relevance to diabetes mellitus. Science $200: 21-27$

18. McDonald JM, Davis JE (1979) Glycosylated hemoglobins and diabetes mellitus. Human Pathol 10: 279-291
19. Bunn HF (1981) Evaluation of glycosylated hemoglobin in diabetic patients. Diabetes 30:613-617

20. Parfentjev IA, Johnson ML, Cliffton EE (1953) Determination of plasma fibrinogen by turbidity with ammonium sulfate. Arch Biochem 46: 470-480

21. Imaizumi K, Shiga T (1983) Effect of immunoglobulin and IgGfragments on the human erythrocyte aggregation, studied by a rheoscope combined with image analyzer. Biorheology 20: 569-577

22. Imagawa S, Makino N, Abe T, Sugita $Y$ (1982) Kinetic studies on the ligand binding of glycosylated hemoglobin. Biochem Biophys Res Commun 107: 1355-1360

23. Peterson CM, Jones RL, Koenig RJ, Melvin ET, Lehman ML (1977) Reversible hematologic sequelae of diabetes mellitus. Ann Int Med 86: 425-429

24. Chien S, Jan K-M (1973) Red cell aggregation by macromolecules: roles of surface adsorption and electrostatic repulsion. J Supramolec Struct 1: 385-409

25. Wells RE, Gawronski TH, Cox PJ, Perera RD (1964) Influence of fibrinogen on flow properties of erythrocyte suspension. Am J Physiol 207: 1035-1040

26. Rand PW, Barker N, Lacombe E (1970) Effect of plasma viscosity and aggregation on whole-blood viscosity. Am J Physiol 218: $681-688$

27. van Haeringen $\mathrm{NJ}$, Glasius E (1970) The relation between rouleaux formation in blood and fibrinogen content in plasma. Clin Chim Acta 29: 55-60

28. Schmid-Schönbein H, Rieger H, Gallasch G, Schachter H (1977) Pathological red cell aggregation (clump aggregation). Bibl Anat 16: $484-489$

29. Maeda N, Kon K, Imaizumi K, Sekiya M, Shiga T (1983) Alteration of rheological properties of human erythrocytes by crosslinking of membrane proteins. Biochim Biophys Acta 735: 104-112

30. Maeda T, Akiyama M, Ashikaga M, Yokose T, Isogai Y (1982) Red cell filtrability and internal viscosity in diabetic microangiopathy. Microcirc Res 24: 216

31. Miller JA, Gravallese E, Bunn HF (1980) Non-enzymatic glycosylation of erythrocyte membrane protein, relevance to diabetes. J Clin Invest 65: 896-901

32. McMillan DE, Brooks SM (1982) Erythrocyte spectrin glycosylation in diabetes. Diabetes 31 (suppl) 3:64-69

33. Otsuji S, Baba Y, Kamada T (1981) Erythrocyte membrane microviscosity in diabetes. In: Pfeiffer EE, Rall JE (eds) Pathologic concepts of diabetic microangiopathy. Thieme-Stratton, New York, pp $97-102$

34. Guthrov CE, Morris MA, Day JF, Thorpe SR, Baynes JW (1979) Enhanced nonenzymatic glycosylation of human serum albumin in diabetes mellitus. Proc Natl Acad Sci US 76: 4258-4261

35. Yue DK, Morris K, McLennan S, Turtle JR (1980) Glycosylation of plasma protein and its relation to glycosylated hemoglobin in diabetes. Diabetes 29: 296-300

Received: 6 June 1983

and in revised form: 17 August 1984

Dr. Takeshi Shiga

Department of Physiology

School of Medicine

Ehime University

Shigenobu, Onsen-gun

Ehime 791-02

Japan 